\title{
OBSERVATIONS AND MODELS OF TURBULENCE DURING HEAT EVENTS IN COMPLEX URBAN COASTAL REGIONS USING MULTIPLE DOPPLER WIND LIDARS MARK AREND ${ }^{1}$, DAVE A. LIGON ${ }^{2}$, DERYCK JAMES ${ }^{2}$, MARK J. CAMPMIRE ${ }^{3}$, DAVId MELECIO-VAZqueZ ${ }^{4}$, Jorge GONZALEZ ${ }^{4}$, Fred MOSHARY ${ }^{1}$ \\ ${ }^{I}$ NOAA-CREST and Electrical Engineering Department, CUNY CCNY, NY, NY, 10031 \\ ${ }^{2} U$. S. Army Research Laboratory, Adelphi, MD, 20783 \\ ${ }^{3}$ Civil, Architectural, and Environmental Engineering Dept. UT Austin, TX \\ ${ }^{4}$ NOAA-CREST and Mechanical Engineering Department, CUNY CCNY, NY, NY, 10031 \\ *Email:marend@.ccny.cuny.edu
}

\begin{abstract}
Multiple Doppler Lidars have been co-operated in the NYC region during the summer of 2018 to provide detailed observations of the turbulent atmosphere especially during heat wave events. The co-operating Doppler Lidar observations allow for mean flows to be distinguished from complex flows so that a better understanding of the transport of air masses can be provided to investigate the fidelity of high resolution numerical weather prediction models that are being developed to interpret and model turbulence during such events.
\end{abstract}

\section{INTRODUCTION}

Understanding the dynamics of ground and upper level pollutant transport in urban coastal areas during heat wave events is becoming a major concern. Even though there have been many advancements on the modeling capabilities to predict the occurrences of such episodes ${ }^{1}$, there is a need to improve the observational capabilities. Multiple Doppler Lidars can be operated in a collaborative mode to provide detailed observations of the flow of air mass ${ }^{2-3}$. The analysis of the Doppler Lidar return signals using the volume velocity processing (VVP) retrieval technique $^{4-5}$ is an approach that is analogous to the types of inverse modeling techniques that are becoming popular in Data Science. By using the VVP technique in conjunction with forward dynamical models allows both inverse and forward modeling techniques to be implemented that can bring insight to the complexity of turbulent flows. This will advance previous observational studies focused on urban coastal regions where the forcings encompass complex thermodynamic and geographic effects ${ }^{6}$ during major heat events ${ }^{7}$.

\section{METHODOLOGY}

A heat event in NYC that occurred on July 2nd, 2018 was observed and modeled. Multiple Doppler Lidars were operated in unison and scan strategies were chosen so that the complexity of the urban coastal flows could be revealed. Fig. 1 shows the three Doppler Lidars (A Halo Streamline, a Halo Pro and a Vaisala/Leosphere 200S) located on top of a roof in upper Manhattan in NYC and the location of these instruments ( N 40.82187, W 73.94789) on a map.

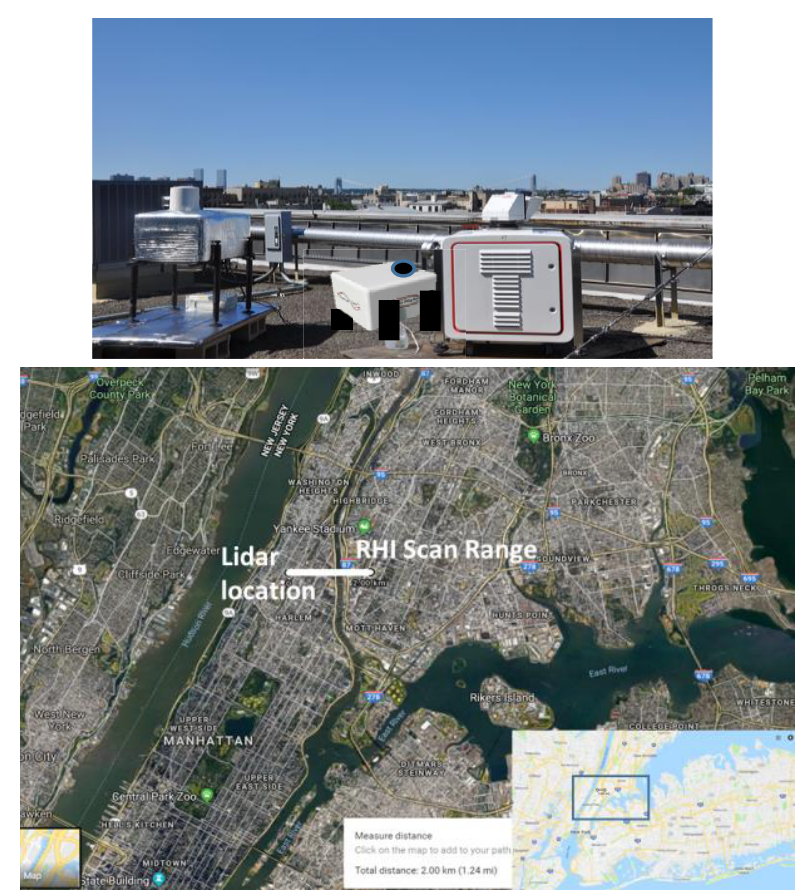

Fig. 1 Siting of Doppler Lidars in NY City 
A number of different scans were selected from the various Doppler Lidars to observe mesoscale and microscale flows. Fig. 2 represents the types of scan strategies.

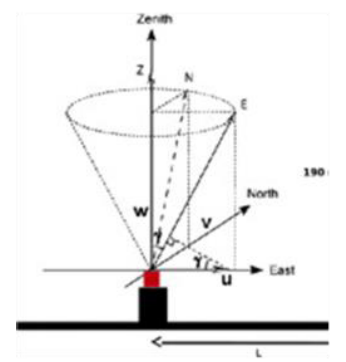

Conical Scan: Profiles mean wind fields.

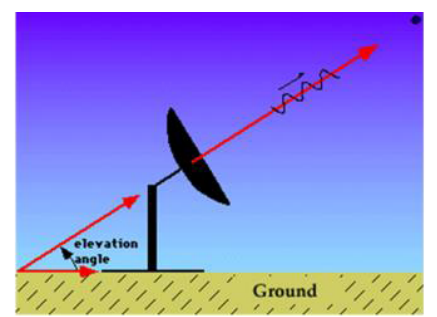

Range Height Indicator (RHI) scan: Lidar is scanned in Elevation at a fixed Azimuth (East in this case)

\section{Fig. 2 Conception of Lidar Scan Strategies}

The Halo Pro Doppler Lidar was programmed to perform Conical Scans to observe the vertical profile of the mean flows. Range Height Indicator (RHI) Scans were implemented on the Halo Streamline so that the VVP processing method can be used to invert the lidar returns. The Azimuth angle for the RHI Scans were fixed (pointed due East) and the Elevation angel was varied between 0 and 90 degrees. The scans implemented on the 200S Doppler Lidar were switched between Vertical Staring for 2 minutes and Doppler Beam Swinging (DBS) for 5 minutes. By comparing these observations with the outputs from a numerical weather prediction model that takes in to account urban-coastal effects (uWRF) ${ }^{8}$, the dynamics of the vertical structure of the atmosphere becomes apparent.

\section{RESULTS}

Plots of the vertical profiles of the horizontal wind velocity a function of time (on July $2^{\text {nd }}, 2018$ ) are plotted in the Figures 3, 4 and 5. Fig. 3 is the Vaisala/Leosphere 200S Doppler Lidar, Fig. 4 is the Halo Pro Doppler Lidar and Fig. 5 is the output from the uWRF model. These plots show some similarities of the turbulent activities on this heat wave event. The horizontal wind speeds are reasonably low until the evening. At around 15:00 EDT both the observations and the uWRF plots show a significant low level jet that forms. To portray the formation of turbulent structures throughout the day and into the evening, the results from the RHI scans of the Halo Streamline are shown in Figures 6-8.

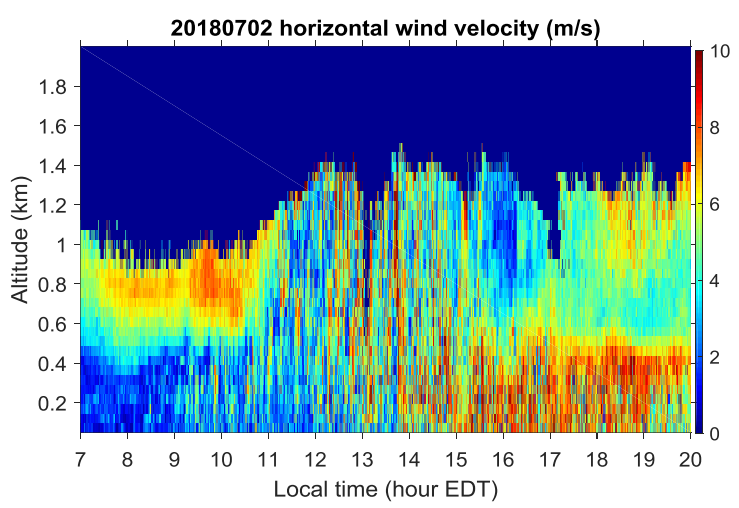

Fig. 3 200S Horizontal Wind Speed

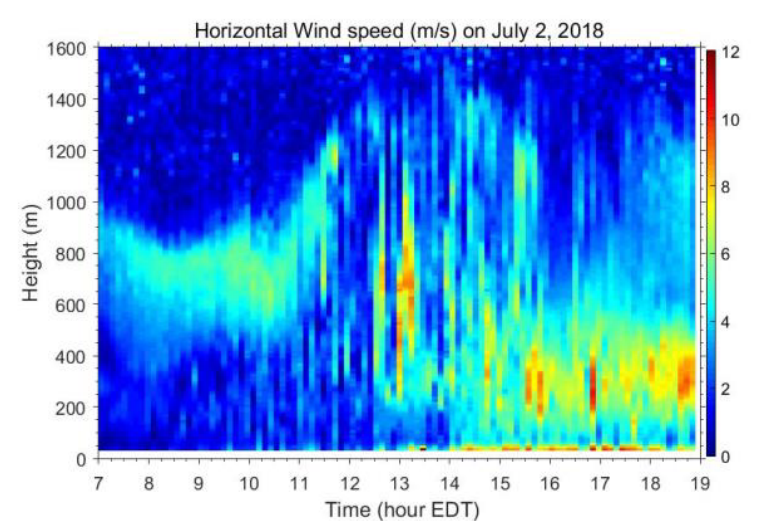

Fig. 4 Halo Pro Horizontal Wind Speed

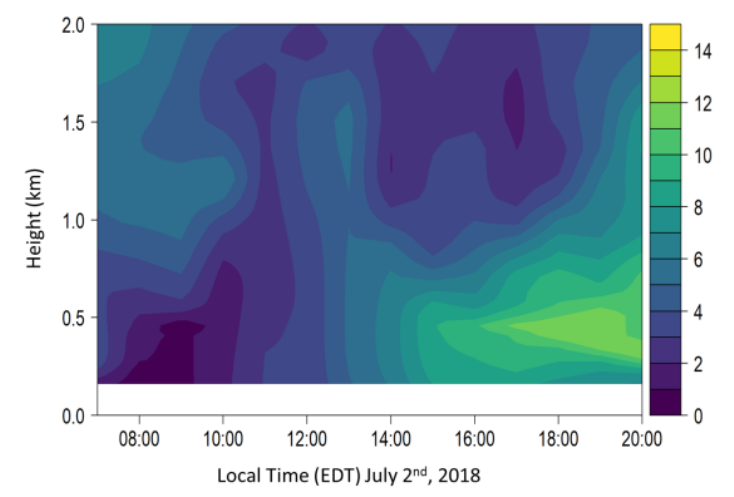

Fig. 5 uWRF Horizontal Wind Speed

Plots of the Halo Pro and Streamline Lidars results are shown in Figures 6-8 to show how the turbulent eddies evolve throughout the day. The Pro plots $(6 a, 7 a, 8 a)$ show how the the evolution of the low level jets and how horizontal direction has a slight amount of vertical shear. For the RHI plots $(6 b, 7 b, 8 b)$, the $x$-axis of these plots is the horizontal distance from the lidar, the $y$ axis is the 
height above ground level, the color scales represent the line of sight wind speed and the arrows represent the wind direction only along the direction that the RHI scans are performed (East/West and vertical). Figure 7 and Figure 8 clearly demonstrate how the turbulent structures become more apparent later in the day.

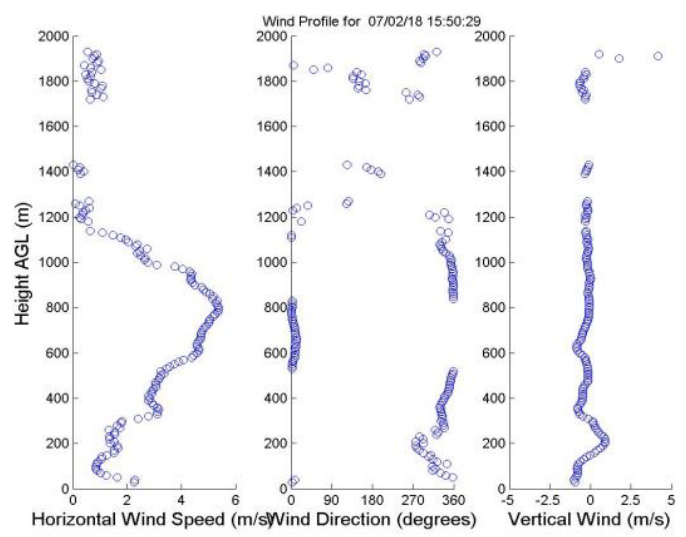

Fig. 6a Halo Pro profiles at 11:30 EDT

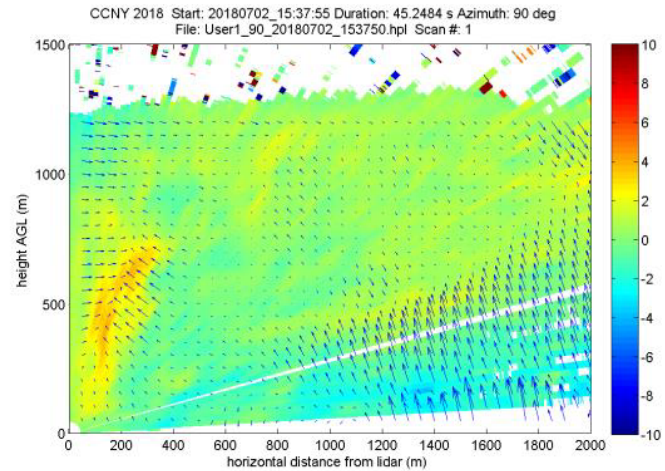

Fig. 6b Halo Streamline RHI output 11:30 EDT

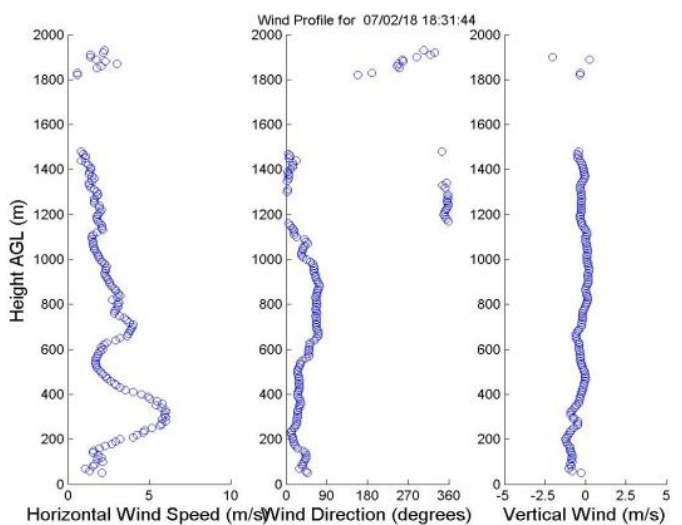

Fig. 7a Halo Pro profiles at 13:30 EDT

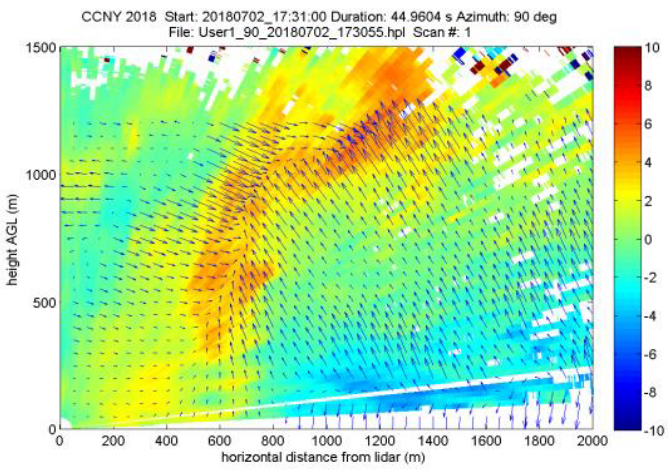

Fig. 7 Halo Streamline RHI output 13:30 EDT

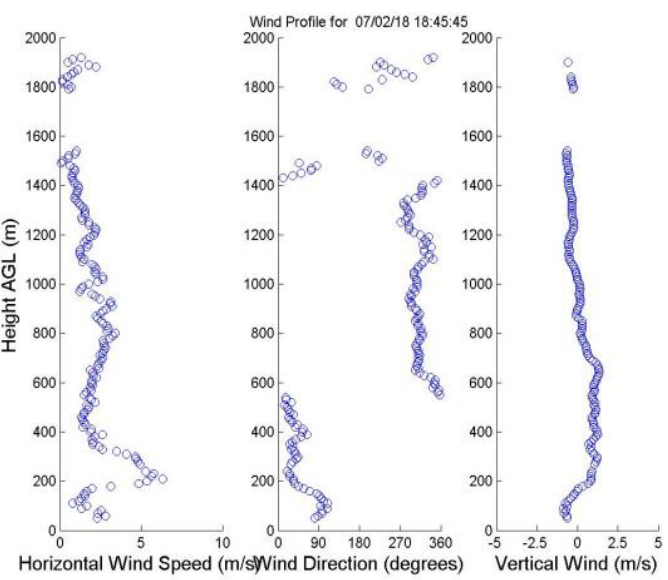

Fig. 8a Halo Pro profiles at 13:45 EDT

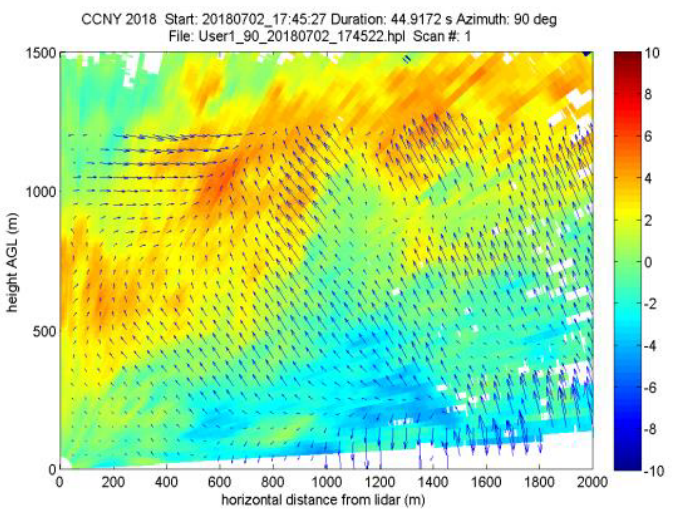

Fig. 8b Halo Streamline RHI output 13:45 EDT

Analysis of these events was made to explore the turbulent structures that evolved over the period 
of the event and the low level jets. The analysis performed in this study when combined with evolving Doppler Lidar inversion techniques ${ }^{7-9}$, will be able to advance the methods described in this study.

\section{ACKNOWLEDGEMENTS}

This study is partly supported by the NESCAUM project \#2411, New York State Energy Resources Development Authority (agreement \# 100415) and the NOAA under the CREST Cooperative Agreement Grant \# NA16SEC4810008.

\section{REFERENCES}

[1] Kaihui Zhao, Yunxuan Bao, Jianping Huang, Yonghua Wu, Fred Moshary, Mark Arend, Yongwei Wang, Xuhui Lee, "A high-resolution modeling study of a heat wave-driven ozone exceedance event in New York City and surrounding regions", Atmos. Environ., 2019, 199, 368-379

[2] Newsom, Rob \& Calhoun, Ron \& Ligon, David \& Allwine, Jerry. (2008), "Linearly Organized Turbulence Structures Observed Over a Suburban Area by Dual-Doppler Lidar. Boundary-Layer Meteorology", 127. 111-130. 10.1007/s10546-007-9243-0.

[3] Newsom RK, Ligon D, Calhoun R, Heap R, Cregan E, Princevac M. "Retrieval of microscale wind and temperature fields from single- and dual-Doppler lidar data", Journal of Applied Meteorology. 2005 Sep;44(9):1324-

1344. https://doi.org/10.1175/JAM2280.1

[4] Boccippio, D. J., 1995, “A diagnostic analysis of the VVP single-Doppler retrieval technique", J. Atmos. Oceanic Technol., 12, 230-248.

[5] Waldteufel, P., and H. Corbin, 1979,"On the analysis of single-Doppler radar data", J. Appl. Meteor., 18,532-542.

[6] Melecio-Vázquez, D., Ramamurthy, P., Arend, M. et al., "Thermal Structure of a Coastal-Urban Boundary Layer", Boundary-Layer Meteorol (2018) 169: 151. https://doi.org/10.1007/s10546-018-0361-7

[7] Ramamurthy P, González J, Ortiz L, Arend M, Moshary F (2017) Impact of heatwave on a megacity: an observational analysis of New York City during July 2016. Environ Res Lett 12:54011. https://doi.org/10.1088/1748-9326/aa6e59

[8] Gutiérrez E, González JE, Martilli A, Bornstein R, Arend M (2015) Simulations of a heat-wave event in New York City using a multilayer urban parameterization. J Appl Meteorol Climatol 54:283-
301. https://doi.org/10.1175/JAMC-D-14-0028.1

[7] A. Choukulkar, R. Calhoun, B. Billings and J. D. Doyle, "A Modified Optimal Interpolation Technique for Vector Retrieval for Coherent Doppler LIDAR," in IEEE Geoscience and Remote Sensing Letters, vol. 9, no. 6, pp. 1132-1136, Nov. 2012. doi: 10.1109/LGRS.2012.2191762

[8] Abdelazim, Sameh; Santoro, David; Arend, Mark; Moshary, Fred and Ahmed, S., "Development and Operational Analysis of an All-Fiber Coherent Doppler Lidar System for Wind Sensing and Aerosol Profiling," in IEEE Transactions on Geoscience and Remote Sensing, vol. 53, no. 12, pp. 6495-6506, Dec. 2015. doi: 10.1109/TGRS.2015.2442955

[9] Abdelazim, Sameh; Santoro, David; Arend, Mark; Moshary, Fred; Ahmed, Sam. 2018. "A Hardware Implemented Autocorrelation Technique for Estimating Power Spectral Density for Processing Signals from a Doppler Wind Lidar System." Sensors 18, no. $12: 4170$ 